To the paper

\title{
Determination of carbon, nitrogen and phosphorus in cattail using cold neutron prompt-gamma activation analysis
}

L. Zhao, L. Robinson, R. L. Paul, R. R. Greenberg, S. L. Miao

appeared in the Journal of Radioanalytical and Nuclear Chemistry, Vol. 263, No. 3 (2005) 805-810.

In page 809 , the caption of Fig. 1 should read:

Fig. 1. H and disk thickness effect on the sensitivities of P (1), C (2) and N (3). Uncertainty at 95\% confidence level 